\title{
SPARE THE AIR - COOL THE CLIMATE
}

\author{
JACK P. BROADBENT \\ Bay Area Air Quality Management District, USA
}

\begin{abstract}
The Bay Area Air Quality Management District (District), the local air pollution control agency for the nine-county region of the San Francisco Bay Area in California, has developed the first multipollutant-multi-sector plan. This plan integrates measures to achieve and maintain California state and US ambient air quality standards, reduce smog pollution (ozone and particulate matter) and toxic air contaminants, eliminate disproportionate impacts on communities and reduce greenhouse gases that contribute to the earth's changing climate. This article describes the plan, focusing on the specific strategies the District and its partner agencies will rely upon to address the threat of air pollution and climate change in the San Francisco Bay Area of California. This plan serves as a model for integrating air pollution and climate change programmes at the local level. The plan also provides a bold vision for addressing climate change by visualizing what the Bay Area may look like in a post-carbon year 2050 where we will live, how we will travel, what we will produce, and what we will consume.

Keywords: air, quality, climate, change, control, communities, management, plan, strategy.
\end{abstract}

\section{INTRODUCTION}

The Bay Area Air Quality Management District (District) (BAAQMD) has developed the first multi-pollutant-multi-sector plan that integrates measures to achieve and maintain California state and US ambient air quality standards, reduce smog pollution (ozone and particulate matter) and toxic air contaminants (TACs), eliminate disproportionate impacts on communities and reduce greenhouse gases (GHGs) that contribute to the earth's changing climate. This article describes the plan, focusing on the specific strategies the District and its partner agencies will rely upon to address the threat of air pollution and climate change in the San Francisco Bay Area of California. This plan serves as a model for integrating air pollution and climate change programmes at the local level.

\section{THE BAY AREA AIR QUALITY MANAGEMENT DISTRICT}

The District serves as the local air pollution control agency for the nine-county region of the San Francisco Bay Area in California. It was established in 1955 and is comprised of 350 staff and a board of 24 local elected leaders. BAAQMD is an independent agency created under state law. It has been delegated authority to implement the federal and state clean air acts. The mission of the District is to protect and improve public health, air quality and the global climate.

The District is primarily responsible for regulating industrial stationary sources. It has developed and currently enforces a comprehensive programme to limit emissions from nearly all industrial sources. Over 10,000 facilities are regulated by the District. The programme covers the smallest sources such gas stations, household paint, residential water heaters and commercial back-up generators to the largest sources such as chemical plants, cement production facilities, power-generating stations and petroleum refineries. Although the regulatory programme for these sources is generally considered the most stringent in the US, the District also relies on its outreach and incentive programmes to address our air quality and climate goals. 
The District created the 'Spare the Air' outreach programme to educate residents about air pollution, encourage actions to improve air quality in the Bay Area and provide notice when air quality is expected to be unhealthy. As part of the Spare the Air Program, the District asks residents to reduce pollution by making clean air choices every day. This can include walking and biking more often, taking transit, telecommuting or carpooling, driving less, reducing energy consumption at home, and making many other daily choices that improve air quality. During the winter months, the District's Spare the Air Program requires residents to restrict wood burning in fireplaces. This programme has been widely successful in reducing winter time levels of particulate matter (PM).

The District also relies on incentives to help pay for the installation of air pollution control equipment and the establishment and use of the alternative energy sources to displace fossil fuel use by primarily transportation sources. Specifically, the District receives and distributes approximately $\$ 80$ million a year from local, state and federal sources to pay for the installation of diesel particulate filters on trucks, trains, ships and other heavy-duty equipment, replacement of older, more polluting equipment, and electrification of equipment and installation of electric vehicle (EV) infrastructure.

The District maintains an extensive air monitoring network throughout the Bay Area. Thirty-four permanent air monitoring stations continuously collect and transmit air quality information. In addition, the District maintains several portable air monitors for special community scale monitoring efforts. Figure 1 provides a map of the location of air monitoring stations throughout the region. Each of these monitoring stations measures some of the following pollutants: ozone, PM, ultra-fine PM, lead, nitrogen oxide, sulphur dioxide, carbon monoxide, black carbon, TACs, hydrogen sulphide and GHGs. A few air monitors collect lead and two background sites collect upwind and downwind concentrations of GHGs.

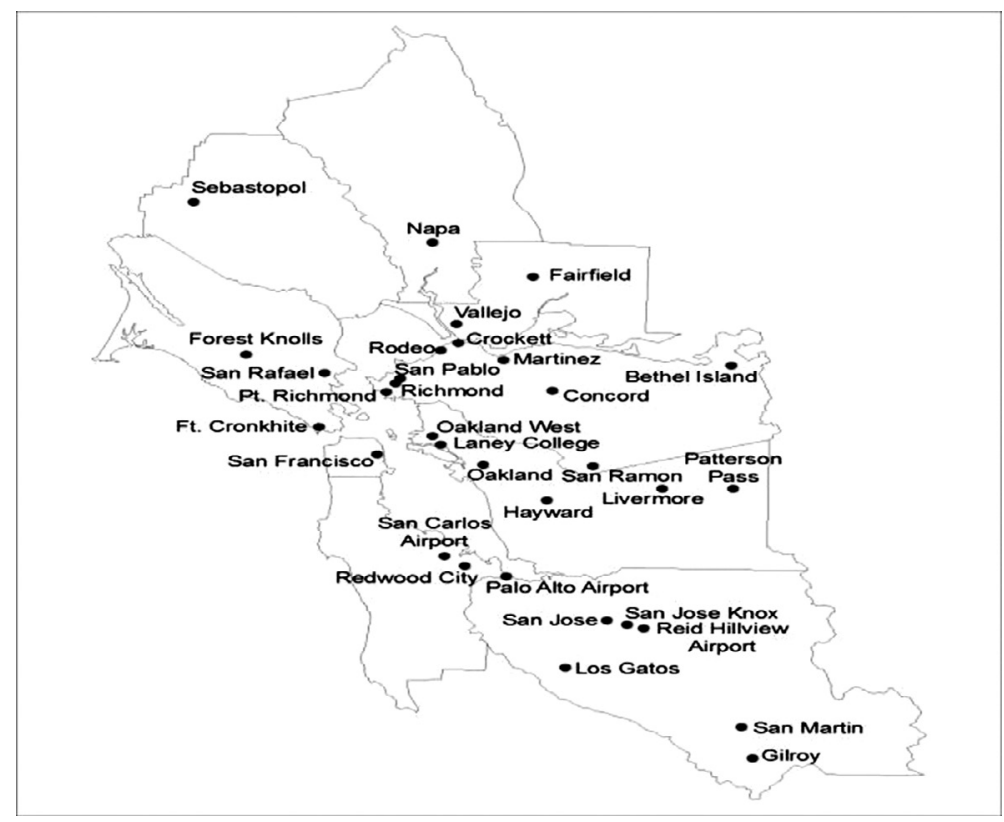

Figure 1: 2016 Air monitoring network. 


\section{KEY POLLUTANTS OF CONCERN}

During summer months, the Bay Area experiences elevated levels of ozone. Although the region does not yet attain California and national ozone standards, the Bay Area ozone levels have been greatly reduced over the past 30 years as shown in Fig. 2. Figures 3 and 4 show the relative combustion of ROG and NOx sources in the Bay Area.

During winter months, the Bay Area experiences elevated levels of PM. PM is a diverse mixture of suspended particles and liquid droplets (aerosols). PM includes elements such as carbon and metals; compounds such as nitrates, organics, and sulphates; and complex mixtures such as diesel exhaust, wood smoke and soil. The Bay Area attains the national 24-hour $\mathrm{PM}_{10}$ standard and the national annual $\mathrm{PM}_{2.5}$ standard largely through the implementation of the wood smoke programme.

Communities around the Bay Area experience elevated levels of TACs. Figure 5 illustrates the communities that are at most risk from TACs. TACs are a class of pollutants that includes hundreds of individual airborne chemical species hazardous to human health. TACs

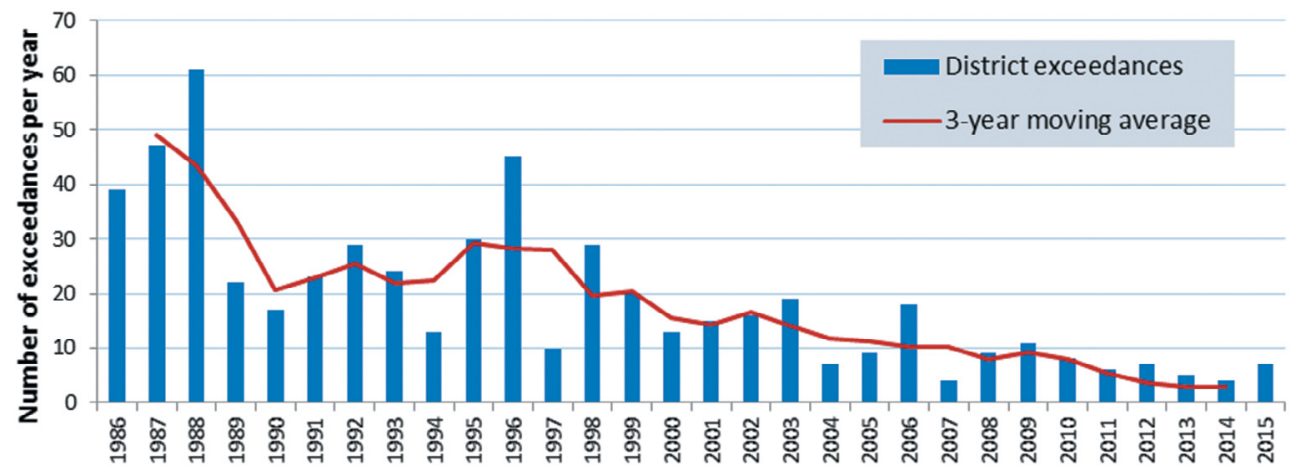

Figure 2: Annual Bay Area days exceeding $0.09 \mathrm{ppm}$ state 1-hour ozone standard at any monitoring station, 1986-2015.

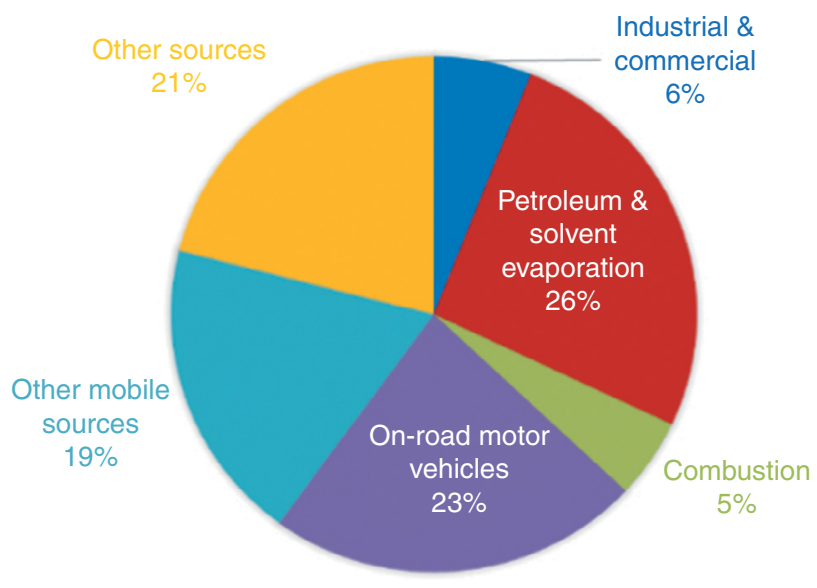

Figure 3: 2015 Annual average ROG emissions by source (259 tons/day). 


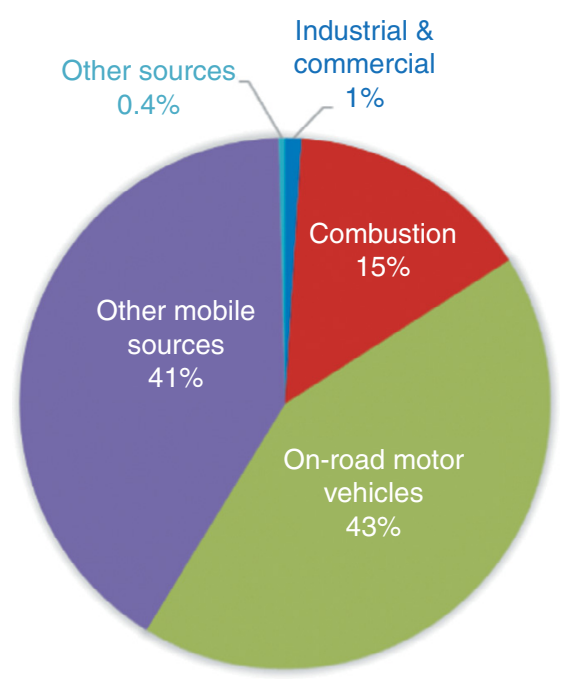

Figure 4: 2015 Annual average NOx emissions by source (298 tons/day).

are primarily regulated at the individual emissions source level based on risk assessment. Human outdoor exposure risk associated with an individual air toxic species is calculated as its ground-level concentration multiplied by an established unit risk factor for that air toxic species. Reducing emissions of TACs and population exposure to these pollutants is a key priority for the District.

Finally, the District works closely with the State of California and the United States Environmental Protection Agency to quantify and reduce GHGs including carbon dioxide $\left(\mathrm{CO}_{2}\right)$, methane $\left(\mathrm{CH}_{4}\right)$, nitrous oxide $\left(\mathrm{N}_{2} \mathrm{O}\right)$, black carbon and fluorinated gases (F-gases): hydrofluorocarbons (HFCs), perfluorocarbons (PFCs) and sulphur hexafluoride ( $\mathrm{SF}_{6}$ ). After increasing rapidly in past decades, GHG emissions throughout California and the Bay Area have levelled off. However, to prevent the most dangerous climate change scenarios, we must reduce GHG emissions greatly. It is especially important to rapidly reduce emissions of those GHGs with very high global warming potential, such as methane and black carbon.

\section{THE CONTROL STRATEGY}

The control strategy in this plan serves as the backbone of the plan, and builds upon existing regional, state and national programmes that have successfully reduced air pollution and improved public health over the past several decades. The control strategy is based on four key priorities:

- Reduce emissions of criteria air pollutants and TACs from all key sources

- Reduce emissions of super-GHG pollutants such as methane

- Decrease demand for fossil fuels

- Increase efficiency of energy, buildings and transportation sectors

- Reduce demand for vehicle travel, and high-carbon goods and services

- Decarbonize our energy system

- Make the electricity supply carbon-free

- Electrify the transportation and building sectors 

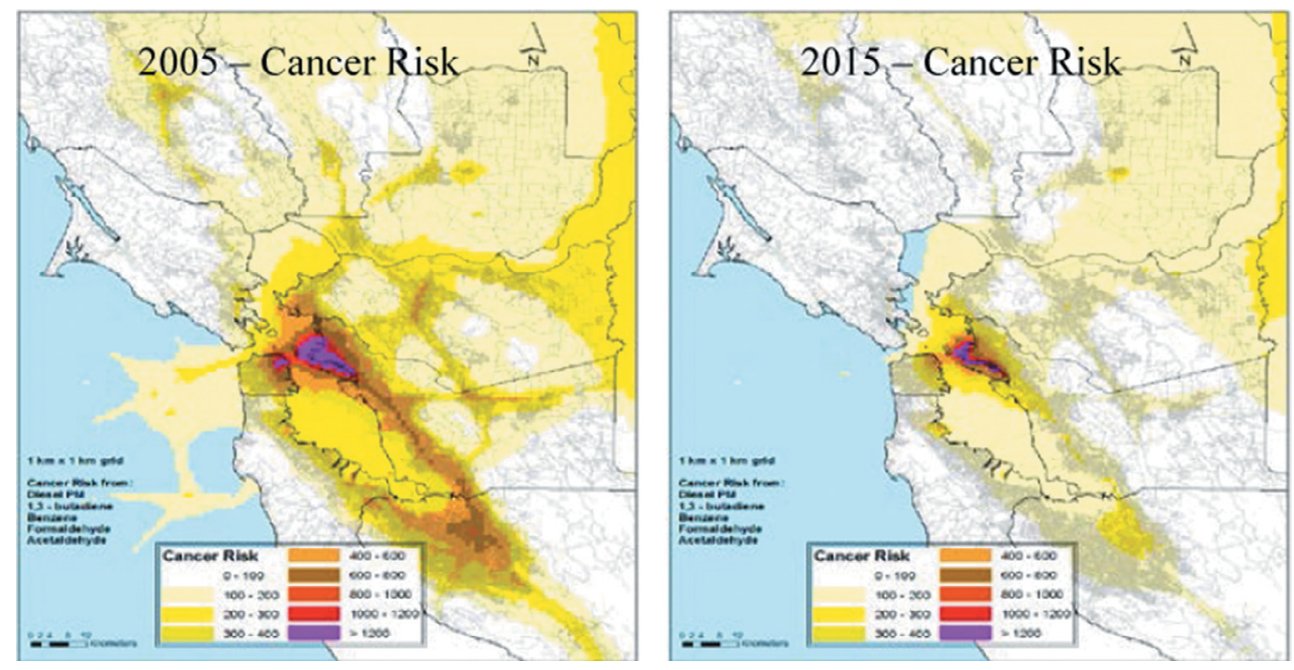

Figure 5: Communities most at risk.

The plan relies on a multi-pollutant planning approach. Multi-pollutant planning can maximize reductions across all air pollutants and climate pollutants, while minimizing any potential emission trade-offs. By analysing air pollutants on the basis of their relative harm to public health, as well as their potency in heating the climate, multi-pollutant planning also provides a means to maximize public health and climate protection benefits. In addition, multi-pollutant planning can help to ensure that our efforts to improve air quality focus on reducing the most harmful air pollution in the communities that are most impacted by air pollution.

The plan contains over 85 separate control measures that describe specific actions targeted at all sources of air pollutants in the Bay Area. The control measures are categorized within the following sectors: industrial sources, transportation, energy, buildings, agriculture, natural and working lands, waste management, and water. The plan also contains measures focused on short-lived climate pollutants with high global warming potential such as methane and black carbon. The control measures contained within each of these sectors are described below.

\section{INDUSTRIAL SOURCES}

The District has developed and currently enforces a comprehensive programme to limit emissions from industrial sources. Nearly all industrial sources are regulated through processspecific rules within the Bay Area. Over 10,000 facilities are regulated by the District. This programme includes the smallest sources such gas stations, household paint, residential water heaters and commercial back-up generators to the largest sources such as chemical plants, cement production facilities, power-generating stations and petroleum refineries. Although the regulatory programme for these sources is generally considered the most stringent in the United States, this plan calls for further reduction of emissions from these sources. Nearly half of the measures in the plan are directed at industrial sources. Each of these measures will be developed as a new regulation or through the modification of an existing regulation. A few examples are described below. 
The Bay Area is home to five petroleum refineries. These sources are the largest stationary sources of ROG, NOx and GHGs in the Bay Area. The plan proposes to further reduce emission from different processes within these refineries. For the fluid catalytic cracking units, which are typically the largest sources of PM in a refinery, the plan calls for further ammonia optimization to achieve reductions of condensable PM. For equipment leaks, the plan proposes to further limit fugitive emissions of volatile organic compounds and methane from valves, flanges and other potential leak points in refineries. Flaring operations and sulphur recovery units at refineries are also targeted in the plan.

To address the impact of TACs from stationary sources in communities in the Bay Area, the plan is proposing a measure that will lower existing risk management standards for sources. Currently, industrial sources, whose risk exceeds 100 in a million, must reduce their emissions to below this level. The plan is proposing to require all stationary sources to meet a 10 in a million standard over time. This measure is designed to reduce the public's exposure to cancer-causing compounds and further protect impacted communities in the Bay Area.

To reduce methane from stationary sources, the plan calls for a basin wide methane strategy to better quantify emission estimates and identify control methodologies. Specifically, natural gas processing and distribution systems are being evaluated for further reduction of methane as well as landfill and waste water treatment facilities. These facilities are already controlled, and further emission reduction opportunities are under evaluation in coordination with partner agencies.

The plan also calls for strengthening the District's odour programme. The District is currently evaluating new air monitoring technologies and improved enforcement methods to enhance its odour response programme and better serve the public.

\section{TRANSPORTATION}

The transportation sector remains the largest source of GHGs, ozone precursors (ROG and NOx) and TACs in the Bay Area. This sector is also a major source of fine PM. The plan proposes measures to further reduce emissions of light-, medium- and heavy-duty vehicles. The overall strategy in the plan calls for the introduction of ever increasing motor vehicle control technologies in coordination with reducing demand for vehicle use through land use planning and promoting more use of transit.

Key elements of the strategy to reduce transportation emissions include the following:

- Collaborate with partner agencies to reduce motor vehicle travel, by promoting alternative means of transportation, and partnering with employers to expand commuter benefits.

- Collaborate with local governments to direct future development to mixed-use neighbourhoods that are well served by transit and provide safe and convenient bicycle and pedestrian access to shopping and services.

- Continue to work with Bay Area ports and the neighbouring communities to reduce emissions from the freight sector, including heavy-duty trucks, ships, and locomotives.

- Accelerate the retirement of older, high-emitting vehicles.

- Rapidly expand the number and the percentage of zero emission vehicles (battery electric and fuel cell) in the Bay Area fleet and provide the charging/fuelling infrastructure needed to support them.

- Promote the use of advanced technology, zero (or near zero) emission vehicles in all vehicle types and applications.

- Collaborate with the State of California to enforce regulations on key sources of transportation sector emissions, such as diesel engines, in the most impacted and vulnerable communities. 
- Advocate with state and federal governments to adopt more stringent vehicle tailpipe emission standards and fuel economy standards for all components of the vehicle fleet.

Of particular note, in the plan, is the promotion and use of EV technology. The Bay Area is home to the greatest concentration of EVs in the United States. Although EVs make up only approximately $2 \%$ of the vehicle fleet today, their acceptance is increasing. The District is working extensively with partner organizations such as the State of California and public utilities to implement a comprehensive EV infrastructure strategy across the Bay Area.

\section{ENERGY}

The energy sector includes emissions of criteria pollutants, local air toxics and GHGs from electricity generated and used within the Bay Area, as well as GHG emissions from electricity generated outside the Bay Area that is imported and used within the region. About twothirds of the electricity consumed in the Bay Area is produced within the region and one-third is imported from other areas in and outside California [1]. On average, the energy produced within the Bay Area has a lower fossil fuel content than energy imported from outside the region.

The energy sector currently accounts for an estimated 18\% of total Bay Area GHG emissions. The GHGs emitted by the energy sector are dominated by carbon dioxide $\left(\mathrm{CO}_{2}\right)$, representing approximately $99 \%$ of all GHGs emitted by the sector, with methane $\left(\mathrm{CH}_{4}\right)$ and nitrous oxide $\left(\mathrm{N}_{2} \mathrm{O}\right)$ emitted in far smaller quantities.

California and the Bay Area have already made great strides in reducing GHG emissions from the energy sector through efforts to reduce the fossil fuel content of electricity, which also reduces emissions of criteria pollutants and TACs. California's Renewables Portfolio Standard (RPS), first established in 2002, is one of the most ambitious renewable energy standards in the country [2]. The RPS programme requires investor-owned utilities, electric service providers and community choice aggregators to increase procurement from eligible renewable energy resources to 33\% of total procurement by 2020, and $50 \%$ by 2030 .

The strategy to decrease demand focuses on promoting energy efficiency and conservation. To that end, the District will

- conduct education and outreach about energy-efficiency programmes and financing available to residents and businesses in the Bay Area;

- increase consumer awareness about energy-efficiency benefits by incorporating this message into existing outreach programmes such as Spare the Air, outreach to Bay Area schools, booths at fairs, etc.;

- work with utilities and 'community choice energy' (CCE) providers to develop messaging to decrease electricity demand during peak times;

- distribute information on state and local energy-efficiency programmes to industrial sources.

To further decarbonize the energy sector, the District will

- engage with electric utilities and CCE providers to maximize the amount of renewable energy supplied to the Bay Area;

- support the formation or expansion of CCE programmes;

- support the development of bioenergy to displace electricity generated from fossil fuels; and

- expedite District permitting for new renewable energy, biofuel and high-efficiency combined heat and power facilities. 


\section{BUILDINGS}

The buildings sector includes residential, commercial, governmental and institutional buildings. Buildings generate emissions through energy use for heating, cooling and operating the building, and from the materials used in building construction and maintenance. Energy use in buildings typically includes electricity - often produced elsewhere - as well as natural gas combustion in building furnaces, boilers, water heaters and appliances. In addition to direct emissions from gas combustion, the buildings sector also accounts for a major share, $64 \%$, of regional electricity consumption.

The control measures for the buildings sector will reduce emissions of air pollutants and GHGs by

- increasing the scope and pace of programmes to improve the energy efficiency of existing buildings;

- promoting the use of electricity and on-site renewable energy in both existing and new buildings to reduce fossil fuel consumption; and

- working to ensure that new construction is designed to achieve zero net GHG emissions by 2020 (or the earliest possible date).

\section{AGRICULTURE}

The Bay Area has more than 8,500 agricultural operations that produce a diversity of fruits, vegetables, meat, dairy products and wines. The Bay Area agricultural sector is predominantly comprised of small farms selling niche products locally. Sources of air pollution from agricultural operations include on- and off-road trucks and farming equipment, aircraft for crop spraying, animal waste, pesticide and fertilizer use, crop residue burning, travel on unpaved roads and soil tillage. Although these activities emit a wide range of air pollutants, including ozone precursors (ROG and NOx), PM, ammonia, hydrogen sulphide and nitrogen, the agricultural sector accounts for a small portion of overall Bay Area air pollutant emissions. The District regulates agricultural (biomass) burning but has limited direct regulatory authority over agricultural equipment and soil management.

The agricultural measures focus on reducing criteria pollutants and GHG emissions by

- requiring/and or promoting best practices for manure management and farming techniques to reduce criteria and GHG emissions;

- developing partnerships with the agricultural community to encourage voluntary actions to reduce GHG emissions;

- capturing GHGs by means of carbon sequestration and biogas recovery; and

- providing grants and monetary incentives for dairy digesters or other equipment or practices that reduce GHG emissions.

The agriculture measures include promoting carbon farm plans; providing guidance to local governments on including carbon-based conservation farming measures and carbon sequestration in local climate action plans; and conducting outreach to agriculture businesses on best practices, including biogas recovery, to reduce GHG emissions.

Additionally, the plan calls for promoting the implementation of dairy digester facilities (also known as biogas recovery) at farms to capture methane as an energy source and to reduce methane emissions. 


\section{NATURAL AND WORKING LANDS}

The Natural and Working Lands sector, including forests, woodlands, shrub lands, grasslands, rangelands and wetlands, encompasses 2.8 million acres, nearly two-thirds of the Bay Area's land mass [3]. Approximately two-thirds of this land (1.9 million acres) functions as rangeland suitable for livestock grazing.

The control measures for the natural and working lands sector focus on increasing carbon sequestration on rangelands and wetlands. In addition, a measure will promote urban treeplanting in order to absorb $\mathrm{CO}_{2}$, provide shade to reduce urban heat island effects and increase carbon sequestration in urban areas.

\section{WASTE MANAGEMENT}

On average, landfill gas contains $55 \%$ of methane and $40 \%$ of carbon dioxide, with the remaining 5\% composed of other gases. When landfill gas is collected, and burned in internal combustion engines or flares, methane is reduced but additional pollutants, such as NOx, are created. Composting is also a source of methane and $\mathrm{CO}_{2}$, as well as ROG, PM, and ammonia. Compost facilities and landfills can produce odours if they are not operated and maintained rigorously.

This plan emphasizes the need for early and aggressive action to reduce emissions of methane and other super-GHGs. To this end, the waste management sector measures focus on reducing or capturing methane emissions from landfills and composting facilities, diverting organic materials away from landfills, and increasing waste diversion rates through efforts to reuse, reduce and recycle.

\section{ACHIEVEMENT OF AIR QUALITY STANDARDS}

Figures 6 and 7 show the Bay Area's maximum Expected Peak Day Concentration values by year, starting in 1980 for the 1-hour and 8-hour ozone standards. Also shown are trend lines projected to the level of the standards. Based on past progress, the Bay Area would

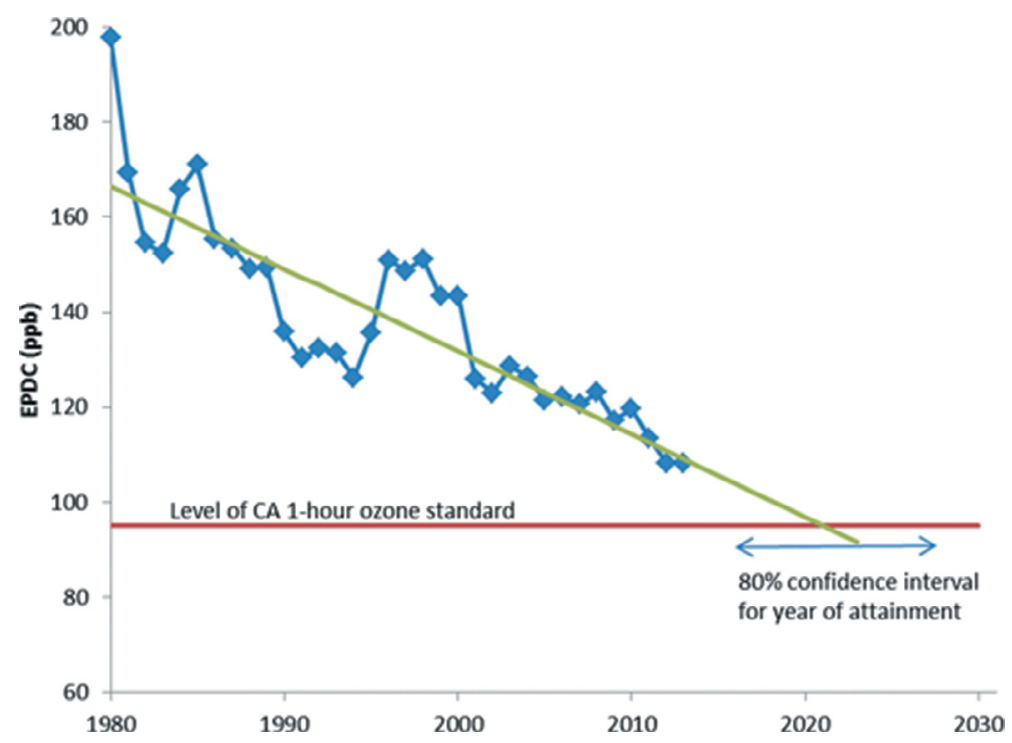

Figure 6: Bay Area progress towards California 1-hour ozone standard and projected year of attainment. 


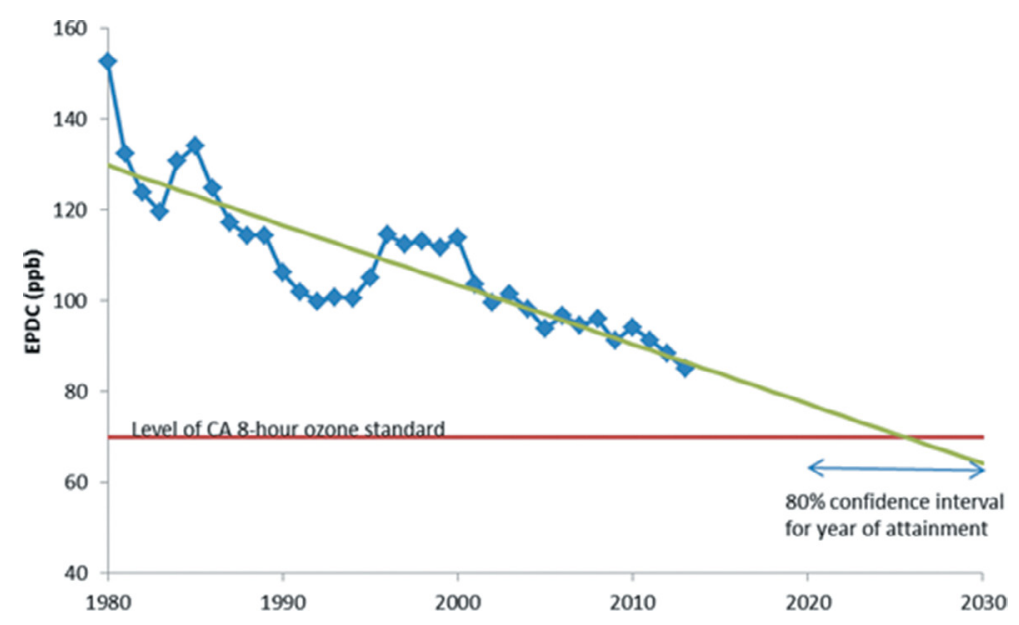

Figure 7: Bay Area progress towards California 8-hour ozone standard and projected year of attainment.

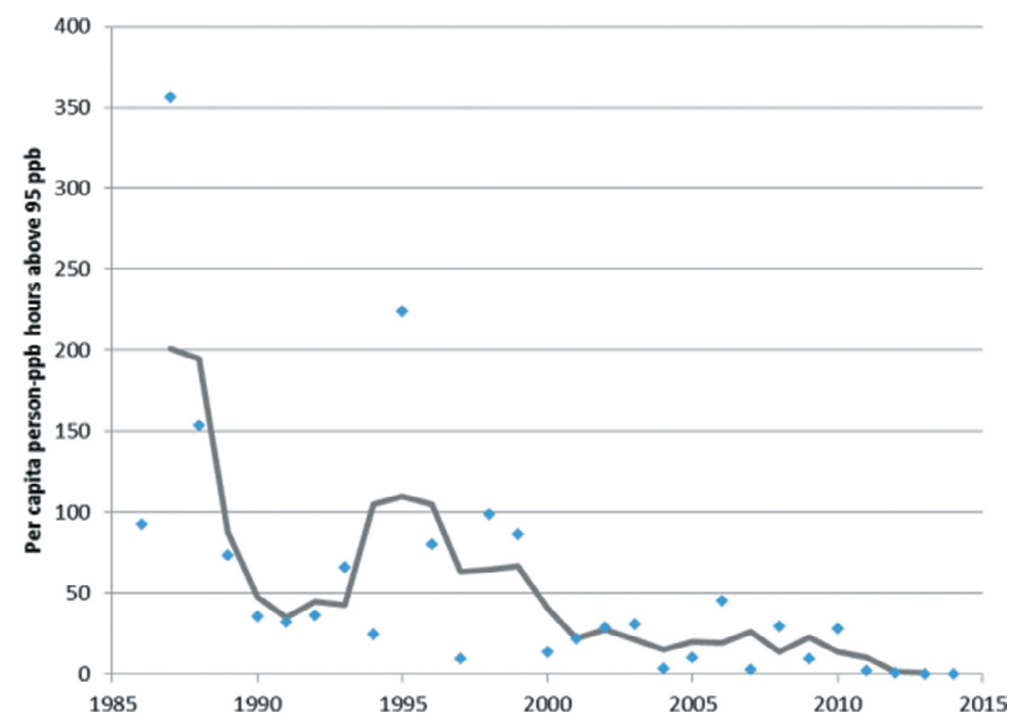

Figure 8: Average per capita population exposure to ozone levels exceeding the state 1-hour standard, 1986-2014.t

meet the 1-hour standard by about 2022, and there is a high probability that the standard would be met between 2016 and 2028. The 8-hour standard is somewhat more stringent. The projected year for meeting the 8-hour standard is 2025 , with a high probability of meeting the standard by 2030 .

Figure 8 shows population-weighted exposures for 1986-1988, 2006-2008 and 2012-2014 for Bay Area counties in relation to the state 1-hour ozone standard. Also shown are the total 
decreases in exposure between these periods. Population exposure decreased from an average of 213 to 1 person-ppb-hours above the standard per year from 1986-1988 to 2012-2014, for an overall reduction of nearly $100 \%$.

\section{LONG-TERM VISION}

The plan also provides a bold vision for addressing climate change by visualizing what the Bay Area may look like in a post-carbon year 2050 - where we will live, how we will travel, what we will produce and what we will consume. Through this vision, we can better discern the policies and actions that we, as a region, need to take in the near to mid-term to embark on the transformation. The plan describes a vision for a thriving region with clean air, a stable climate, a robust natural environment, and a prosperous and sustainable economy. The vision for 2050 is as follows:

Where We Live and Work: Buildings

By 2050 the buildings in which we live, work, learn, shop and socialize will be energy efficient, and they will be heated, cooled and powered by renewable energy.

To eliminate the use of fossil fuels in buildings, we will need to do the following:

- Maximize energy efficiency in both new and existing buildings. Stringent standards already apply to new buildings. However, efforts to retrofit existing commercial and residential buildings will need to be greatly expanded.

- Increase production of on-site renewable energy such as rooftop solar.

- Develop and deploy technologies for on-site energy storage.

- Switch from natural gas to clean electricity, or other renewable energy, for space and water heating, clothes drying, cooking and other domestic uses.

To reduce emissions of PM and black carbon, we will also need to eliminate wood burning.

How and Where We Travel: Transportation

By 2050 the transportation sector will be transformed. We will travel by a combination of EVs, both shared and privately-owned; autonomous public transit fleets offering both fixedroute and flexible-route service; with a large share of trips by bicycling, walking and transit.

- New development will need to offer safe and convenient access to jobs, shopping, and services by transit, bicycle and walking.

- Nearly $90 \%$ of the motor vehicle fleet will need to be zero emission. Heavy-duty vehicles will need to be powered by electricity, or by renewable forms of diesel or other low-carbon liquid fuels.

- The majority of trips will need to be made by walking, bicycling, riding transit or sharing vehicles.

- New technologies and services will reduce the need for personal vehicle ownership. Carsharing services, transportation network companies and autonomous electric-powered vehicles will greatly reduce emissions of air pollutants and GHGs from transportation.

What We Produce: Sustainable Production 
By 2050 the Bay Area economy will be powered by clean, renewable electricity. The region will be a leading incubator and producer of clean energy technologies, and Bay Area industry will lead the world in the carbon efficiency of our products.

- A smart grid interconnecting renewable energy sources will be needed in order to provide nearly $100 \%$ renewable electricity.

- Bay Area industries will be needed to be powered by carbon-free electricity and biofuels.

- The carbon intensity - the amount of carbon it takes to make a given product - of products manufactured in the region will need to be greatly reduced.

- The Bay Area will need to become a hub for the development and production of innovative renewable energy technologies, creating solid jobs requiring diverse education and skills.

\section{What We Consume: 'Conscientious Consumption'}

By 2050 Bay Area residents will need to develop a low-carbon lifestyle. We will greatly reduce our personal GHG consumption (our 'GHG footprint') by driving EVs, living in zero netenergy homes, eating low-carbon foods and purchasing goods and services with low carbon content. Waste will be greatly reduced, any waste products will be re-used or recycled, and all organic waste will be composted and put to productive use.

- The District and partner agencies will develop information campaigns to help Bay Area residents understand the active role they can play in reducing GHG emissions. This will include providing information on the factors that influence their GHG footprint and resources to help make effective choices to reduce their personal GHG footprint.

- Bay Area residents will need to reduce their consumption of carbon-intensive foods and adopt a low-carbon diet for at least some portion of their meals.

- Food waste will need to be greatly reduced and all organic matter will need to be diverted from the waste stream and put to productive use.

\section{IMPLEMENTATION}

To implement the plan, the District will draw upon all the tools and resources at its disposal, including:

- Rule-making: Use its regulatory and permitting authority to adopt and enforce rules to reduce emissions of air and climate pollutants.

- Funding: Provide funds and incentives through its grant and incentive programmes and other sources.

- Best practices: Promote the use of best practices by public agencies and other entities by means of model ordinances, guidance documents, informational campaigns, etc.

- Informational resources: Conduct marketing or media campaigns, disseminate educational materials, and engage with community groups and other organizations.

- Advocacy: Support legislative action at the federal or state level and advocate for funding to support implementation of the measures in the plan.

- Partnerships: Work actively within the region and the state to develop partnerships that can enable business, local government and residents to work and learn together to develop viable air pollution and GHG reduction strategies. 


\section{ACKNOWLEDGEMENTS}

Jean Roggenkamp, Henry Hilken, Christy Riviere, Alison Kirk, Andrea Gordon, Jaclyn Winkle, Dave Burch, Geraldina Grunbaum, Yvette DiCarlo, Abhinav Guha, Idania Zamora, David Holstius, Amir Fanai, David Fairley, Michael Murphy, Dave Vintze, Abby Young, Phil Martien, Greg Nudd, Saffet Tanrikulu, Maricela Martinez

\section{REFERENCES}

[1] Bay Area Air Quality Management District. Bay Area Emissions Inventory Summary Report: Greenhouse Gases Base Year 2011. San Francisco: Bay Area Air Quality Management District, 2015. Print.

[2] State of California, "California Renewables Portfolio Standard (RPS)", April 3, 2017.

[3] Bay Area Open Space Council, The Conservation Lands Network 1.0 Progress Report, Bay Area Open Space Council: Berkeley, CA, 2014.

[4] Bay Area Air Quality Management District. 2017 Clean Air Plan: Spare the Air, Cool the Climate. San Francisco: Bay Area Air Quality Management District, 2017. Print. 